\title{
MUTYH promotes oxidative microglial activation and inherited retinal degeneration
}

\author{
Shunji Nakatake, ${ }^{1}$ Yusuke Murakami, ${ }^{1}$ Yasuhiro Ikeda, ${ }^{1}$ Noriko Morioka, ${ }^{2}$ Takashi Tachibana, ${ }^{1}$ \\ Kohta Fujiwara, ${ }^{1,3}$ Noriko Yoshida, ${ }^{1}$ Shoji Notomi, ${ }^{1}$ Toshio Hisatomi,, Shigeo Yoshida, ${ }^{1}$ \\ Tatsuro Ishibashi, ${ }^{1}$ Yusaku Nakabeppu, ${ }^{2}$ and Koh-Hei Sonoda ${ }^{1}$ \\ 'Department of Ophthalmology, Graduate School of Medical Sciences, Kyushu University, Maidashi, Higashi-Ku, Fukuoka, \\ Japan. 'Division of Neurofunctional Genomics, Department of Immunobiology and Neuroscience, Medical Institute of \\ Bioregulation, Kyushu University, Maidashi, Higashi-Ku, Fukuoka, Japan. ${ }^{3}$ Department of Ophthalmology, Graduate School \\ of Medical Sciences, Akita University, Hondo, Akita, Japan.
}

Oxidative stress is implicated in various neurodegenerative disorders, including retinitis pigmentosa (RP), an inherited disease that causes blindness. The biological and cellular mechanisms by which oxidative stress mediates neuronal cell death are largely unknown. In a mouse model of RP (rd10 mice), we show that oxidative DNA damage activates microglia through MutY homolog-mediated (MUYTH-mediated) base excision repair (BER), thereby exacerbating retinal inflammation and degeneration. In the early stage of retinal degeneration, oxidative DNA damage accumulated in the microglia and caused single-strand breaks (SSBs) and poly(ADP-ribose) polymerase activation. In contrast, Mutyh deficiency in rd10 mice prevented SSB formation in microglia, which in turn suppressed microglial activation and photoreceptor cell death. Moreover, Mutyh-deficient primary microglial cells attenuated the polarization to the inflammatory and cytotoxic phenotype under oxidative stress. Thus, MUTYH-mediated BER in oxidative microglial activation may be a novel target to dampen the disease progression in RP and other neurodegenerative disorders that are associated with oxidative stress.

Conflict of interest: The authors have declared that no conflict of interest exists.

Submitted: April 1, 2016 Accepted: August 17, 2016 Published: September 22, 2016

Reference information: JCI Insight. 2016;1(15):e87781. doi:10.1172/jici.insight.87781.

\section{Introduction}

Retinitis pigmentosa (RP) is a group of inherited diseases that cause progressive retinal degeneration, and $\mathrm{RP}$ is a major cause of adult blindness that affects more than 1.5 million patients globally (1). The main symptoms of RP are night blindness and constriction of the visual field, followed by the loss of central vision due to rod and subsequent cone photoreceptor cell death. Although mutations in more than 50 different genes have been discovered in RP patients (2-4), the biological and molecular mechanisms by which these mutations cause retinal degeneration have not been fully elucidated. The identification of the common pathological processes that underlie RP will be critical to developing novel treatments for RP.

One candidate biological process implicated in the progression of RP is oxidative stress. Oxidation to macromolecules such as lipids, proteins, and nucleic acids is substantially increased in the retina of various animal models of RP $(5,6)$. Systemic treatments with antioxidants and the retinal overexpression of antioxidant genes suppressed the rod and cone photoreceptor cell death in these models (7-11). However, the mechanism by which oxidative stress induces photoreceptor cell death remains largely unexplored.

8-oxo-7,8-dihydroguanine (8-oxoG) is a major oxidized base in DNA (12), and its accumulation is associated with various diseases, including cancer and neurodegeneration (13-15). In an earlier study, we demonstrated that 8-oxoG is increased in the retina of animal models of RP and the vitreous of RP patients (16). In addition, the transgenic overexpression of MutT homolog-1 (MTH1), an enzyme that sanitizes the oxidized nucleotide pool, delayed the photoreceptor cell death in a mouse model of RP (16), suggesting that DNA oxidation is a key event in the mediation of retinal degeneration in RP.

8-oxoG incorporated into the template DNA can easily mispair with adenine $(17,18)$, and these mismatched adenines are excised by MutY homolog (MUTYH), a base excision repair (BER) enzyme against oxidative DNA damage $(19,20)$. However, under severe oxidative stress, MUTYH leads to the excessive 
formation of single-strand breaks (SSBs) of DNA during the BER process $(21,22)$, and this causes neuronal cell death as well as microgliosis in toxin-induced neurodegeneration (23).

Oxidation and inflammation interact strongly during neurodegeneration. Activated microglial cells mediate neuronal cell death through the production of ROS in experimental models of retinal and neuro-degeneration $(24,25)$. In addition, Gill et al. reported that a reduction of antioxidant/detoxifying enzyme in microglial cells enhances glutamate production and neurotoxicity in HIV-associated neurocognitive disorders (26). However, the precise mechanisms that link oxidation and inflammation remain elusive. In the present study of a mouse model of RP, we observed that oxidative DNA damage in the microglia was pivotal for microglial activation, and our findings demonstrated that MUTYH-mediated BER is a critical step in the promotion of retinal inflammation and degeneration.

\section{Results}

Mutyh deficiency protects photoreceptors against cell death and suppresses microglial activation in $r d 10$ mice. The $\mathrm{rd} 10$ mouse is a mouse model of RP with a missense point mutation in the $\beta$-subunit of the rod cyclic guanosine monophosphate (cGMP) phosphodiesterase gene (Pde6b) (27). Point mutations of PDE6 $\beta$ have been detected in autosomal recessive RP patients (28). In rd10 mice, rod photoreceptor cell death begins around postnatal day 18 (P18) and most of the rod photoreceptor cells disappear at P30, followed by cone photoreceptor cell death (27). For the present investigation of the downstream events of DNA oxidation during retinal degeneration, we crossed rd10 mice with $M u t y h^{-/-}$mice to create rd10;Muty $h^{-/-}$mice. There was no obvious retinal abnormality in the $\mathrm{Muty}^{-/-}$mice (Supplemental Figure 1; supplemental material available online with this article; doi:10.1172/jci.insight.87781DS1). A Western blot analysis confirmed that MUTYH expression in the retina was abolished in the rd10; $\mathrm{Mutyh}^{-/-}$mice (Figure 1A). MUTYH deficiency significantly reduced the number of TUNEL-positive cells in the outer nuclear layer (ONL) at P21 (Figure 1, B and C), and it attenuated the loss of rod photoreceptor cells at P26 in the rd10 mice (Figure 1, D and E). In addition, the retinal whole-mount staining for peanut agglutinin (PNA), which selectively binds to cone inner and outer segments, showed that the $\mathrm{rd10} \mathrm{Mutyh}^{-/-}$mice retained more cone photoreceptor cells compared with the rd10; $M u t y h^{+/+}$mice at P42 (Figure $1, \mathrm{~F}$ and $\mathrm{G}$ ).

To assess the influence of MUTYH deficiency on microglial activation, we performed retinal wholemount staining for microglial activation marker Iba-1. The number of Iba-1-positive microglia was significantly decreased in the rd10;Muty $h^{-/-}$mice compared with the rd10;Muty $h^{+/+}$mice at both P21 (Figure $1, \mathrm{H}$ and I) and P42 (Figure 1, J and K). In addition, the microglia in the rd10; $M u t y h^{-1-}$ mice exhibited a relatively inactivated (ramified) morphology (Figure $1, \mathrm{H}$ and $\mathrm{J}$ ).

MUTYH triggers SSB formation and PARP activation during retinal degeneration in rd10 mice. Excessive oxidative DNA damage results in the formation of SSBs during BER, and SSBs in the nucleus and mitochondria mediate the activation of poly(ADP-ribose) polymerase (PARP) and calpain, respectively (21). We previously showed that nuclear DNA oxidation and PARP-apoptosis inducing factor (AIF) activation occur predominantly in the retina of rd10 mice (16). In the present study, therefore, we investigated whether these pathways are affected by MUTYH deficiency in rd10 mice. The immunostaining for single-strand DNA (ssDNA) showed that there were no SSBs in the ONL of the P14 $\mathrm{rd} 10 ; M u t y h^{+/+}$mice or in the rd10;Muty $h^{-/-}$ mice. Punctate staining of SSBs was observed in the ONL of P17 rd10;Muty $h^{+/+}$mice or rd10;Muty $h^{-/-}$mice (Supplemental Figure 2). Thereafter, MUTYH deficiency substantially prevented the formation of SSBs in the ONL of the P21 rd10 mice (Figure 2, A and B).

PARP is an enzyme activated by SSBs in nuclear DNA (29), and PAR polymer, which is produced on PARP activation, directly induces the nuclear translocation of AIF and cell death $(30,31)$. The increased PAR expression and AIF nuclear translocation observed in the rd10;Muty $h^{+/+}$mice were markedly suppressed in the rd10; Muty $^{-/-}$mice (Figure 2, C and D, and Supplemental Figure 3). These findings indicate that MUTYH-mediated BER is critical for the formation of SSBs and the activation of the PARP pathway in rd10 mice.

Oxidative DNA damage in microglia initiates microglial activation and exacerbates retinal degeneration through MUTYH-mediated BER. We next examined the time-dependent changes of oxidative DNA damage during retinal degeneration and the effect of MUTYH deficiency on DNA oxidation. In the retinas of the rd10; $\mathrm{Mutyh}^{+/+}$mice, there was no obvious 8-oxoG accumulation at P14 (Figure 3A and Supplemental Figure $4 \mathrm{~A}$ ). We observed 8 -oxoG immunoreactivity in the ONL in a punctate pattern at P17 (Figure 3B and Supplemental Figure 4B), and the immunoreactivity was expanded to the ONL diffusely at P21 (Figure 3C and Supplemental Figure 4C). 
A

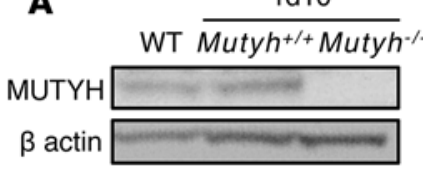

B

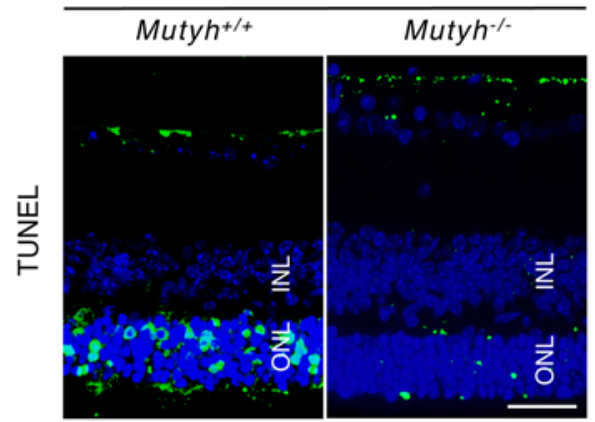

D

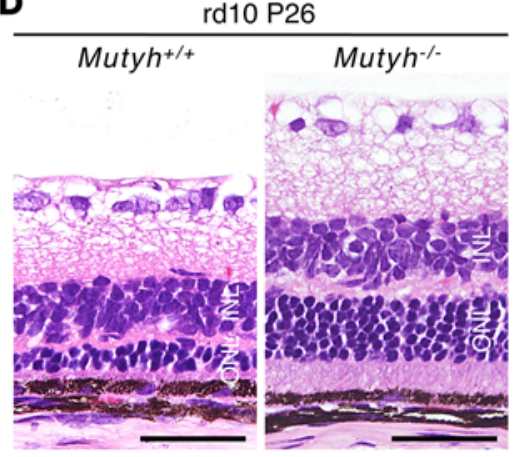

$\mathbf{F}$

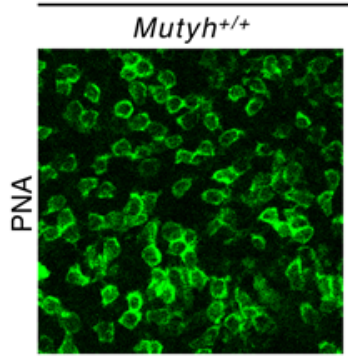

rd10 P42

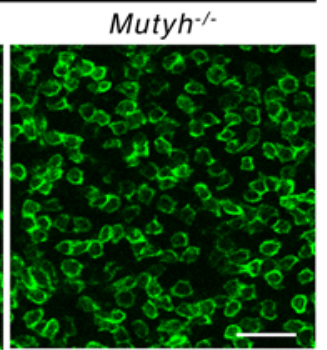

H

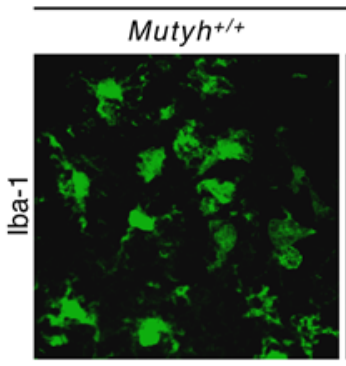

rd10 P21

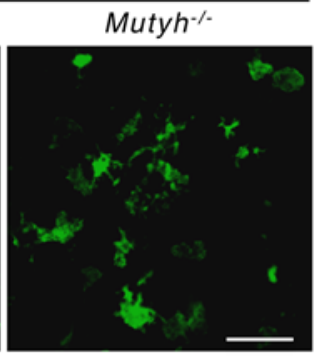

J

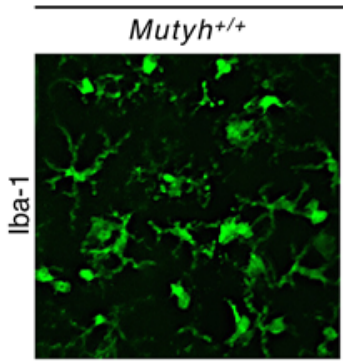

rd10 P42

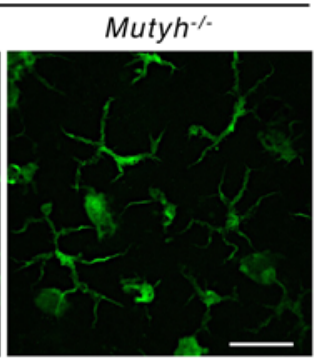

E

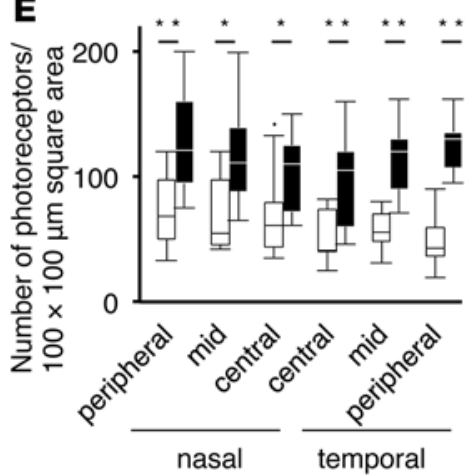

G

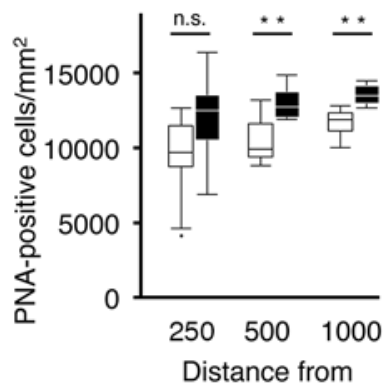

I

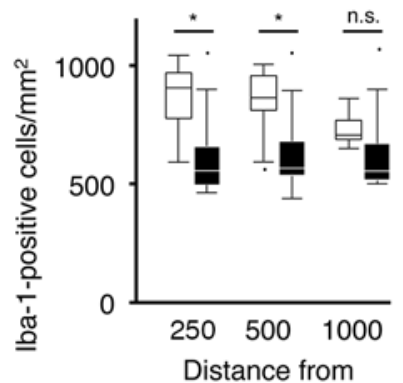

the optic disc $(\mu \mathrm{m})$

$\mathbf{K}$

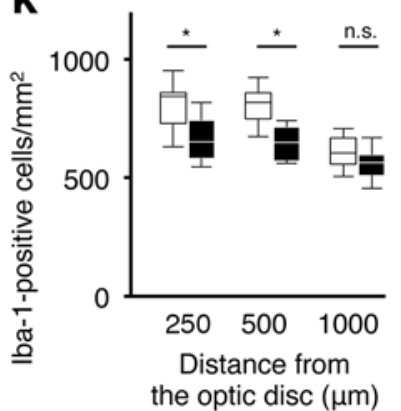

$\begin{array}{ll}\text { C } & \mathrm{rd} 10 ; \text { Muty }^{+/+} \\ \mathrm{rd} 10 ; \text { Mutyh }^{\prime-}\end{array}$

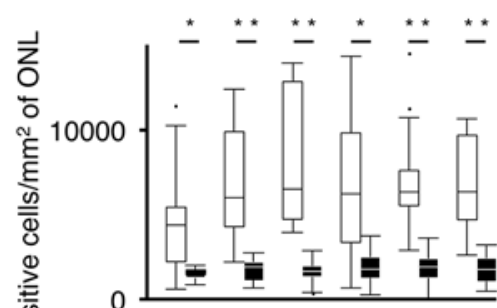

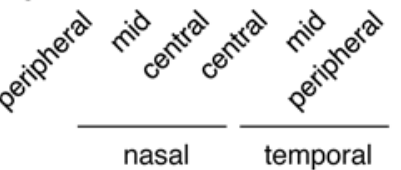

Figure 1. Mutyh deficiency protected photoreceptors against cell death and suppressed microglial activation in rd10 mice. (A) Western blot analysis for MUTYH protein in the retinas from WT, rd10; $\mathrm{Mutyh}^{+/+}$, and rd10; Mutyh/- mice. $\beta$-Actin was used as the loading control. (B and C) TUNEL (green) and DAPI (blue) staining (B) and quantification of TUNEL-positive photoreceptor cells (C) in the retinas of P21 rd10;Muty $\mathrm{h}^{+/+}$mice $(n=8)$ and rd10; Mutyh $^{-/}$mice $(n=7)$. INL, inner nuclear layer; ONL, outer nuclear layer. Scale bar: $50 \mu \mathrm{m}$. (D and $\mathbf{E}$ ) Histological findings of the retina (D) and quantitative analysis of photoreceptor cells (E) in the ONL in P26 rd10;Mutyh ${ }^{+/+}$mice ( $n$ $=10)$ and rd10;Muty ${ }^{-1 /}$ mice $(n=9)$. The number of photoreceptor nuclei in the $10,000-\mu \mathrm{m}^{2}$ area was counted at the peripheral, mid-peripheral, and central regions of the retina. Scale bars: 50 $\mu \mathrm{m}$. (F and $\mathbf{G})$ PNA staining $(\mathbf{F})$ and quantification of PNA-positive cone photoreceptor cells (G) in the retinas of P42 rd10;Mutyh ${ }^{+/+}$mice $(n=8)$ and rd10;Muty $h^{-/-}$mice $(n=6)$. Scale bar: $20 \mu \mathrm{m}$. (H and $\mathbf{I})$ Iba-1 staining $(\mathbf{H})$ and quantification of Iba-1-positive microglia (I) in the retinas of P21 rd10; Mutyh $^{+/+}$mice $(n=7)$ and rd10;Mutyh ${ }^{-/}$mice $(n=7)$. Scale bar: $50 \mu \mathrm{m}$. (J and K) Iba-1 staining (J) and quantification of Iba-1-positive microglia (K) in the retinas of P42 rd10; Muty $h^{+/+}$mice $(n=$ 6) and rd10; Muty $h^{-/-}$mice $(n=6)$. Scale bar: 50 $\mu \mathrm{m}$. Data shown are the combined results for all mice in 2-4 experiments. Data are presented as whisker-box plots. The central horizontal bars indicate the medians, boxes indicate 25 th to 75 th percentiles, and whiskers indicate 1.5 times the interquartile range from the bottom and the top of the box. Outliers are shown as dots. Wilcoxon rank sum tests were performed to assess significance. ${ }^{*} P<0.05,{ }^{* *} P<0.01$. 
A

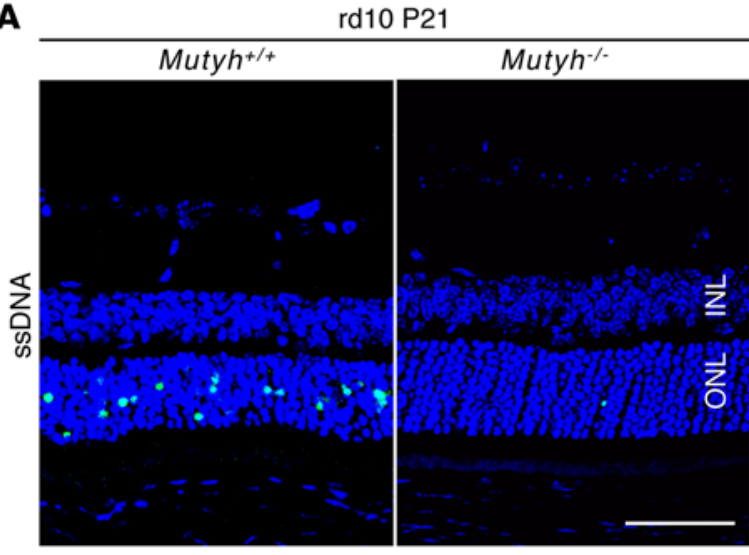

C

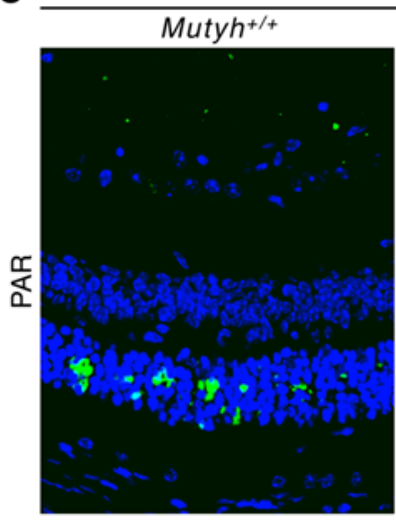

rd10 P21

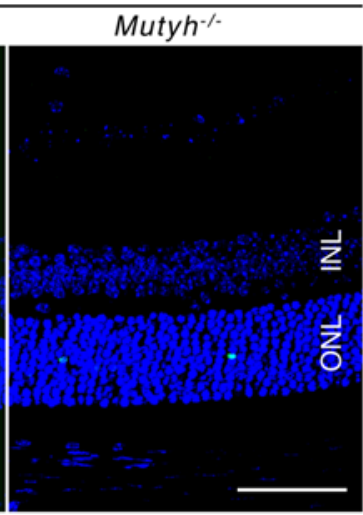

B

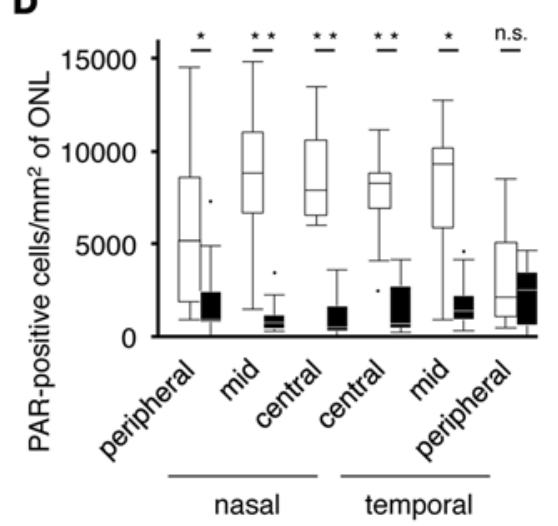

Figure 2. Mutyh deficiency suppressed the formation of SSBs and PARP activation in rd10 mice. (A and B) ssDNA (green) and DAPI (blue) staining (A) and quantification of ssDNApositive cells $(\mathbf{B})$ in the retinas of P21 rd10; Mutyh ${ }^{+/+}$mice ( $n=$ 8) or rd10;Mutyh ${ }^{-1-}$ mice $(n=7)$. INL, inner nuclear layer; ONL, outer nuclear layer. Scale bar: $50 \mu \mathrm{m}$. (C and D) PAR (green) and DAPI (blue) staining (C) and quantification of PAR-positive cells $(D)$ in the retinas of P21

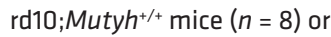
rd10; Mutyh ${ }^{-/-}$mice $(n=7)$. Scale bar: $50 \mu \mathrm{m}$. Data shown are the combined results for all mice in 2-4 experiments. Data are presented as whisker-box plots. The central horizontal bars indicate the medians, boxes indicate 25th to 75 th percentiles, and whiskers indicate 1.5 times the interquartile range from the bottom and the top of the box. Outliers are shown as dots. Wilcoxon rank sum tests were performed to assess the significance. ${ }^{*} P<0.05,{ }^{* *} P<0.01$.

Since MUTYH acts downstream of DNA oxidation, we hypothesized that MUTYH deficiency may not affect the levels of 8-oxoG in rd10 mice. Indeed, there was comparable punctate immunoreactivity of 8-oxoG between the $\mathrm{rd10} \mathrm{Muty}_{\mathrm{h}^{+/+}}$and $\mathrm{rd10}$; $\mathrm{Muty}^{\mathrm{h}^{-/}}$mice at P17 (Figure 3B and Supplemental Figure 4B). However, surprisingly, the 8-oxoG accumulation at P21 was substantially decreased in the rd10; Muty $^{-/-}$mice (Figure 3C and Supplemental Figure 4C). Because the 8-oxoG immunoreactivity detected with or without $\mathrm{HCl}$ pretreatment was comparable, we performed the subsequent experiments with $\mathrm{HCl}$ pretreatment.

To elucidate the mechanisms by which MUTYH accelerates microglial activation, we investigated the cell types associated with DNA oxidation in the early stage of retinal degeneration. Previous studies showed that microglial cells infiltrate into the ONL concomitantly or before the onset of photoreceptor cell death in animal models of RP (32). In the present investigation, the double immunostaining for 8-oxoG and Iba-1 revealed that part of the 8-oxoG signal was colocalized with that of Iba-1 in both the rd10;Muty $h^{+/+}$and rd10; Muty $^{-1-}$ mice at P17 (Figure 4A). At P21, increased 8-oxoG immunoreactivity was observed in the photoreceptor layer, as well as in microglial cells in the rd10; Muty $h^{+/+}$mice, whereas they were substantially prevented in the retinas of the rd10; $\mathrm{Muty}^{-/-}$mice (Figure 4B). Costaining with 8-oxoG, Iba-1, and DAPI showed that the 8-oxoG accumulation was associated with nuclear DNA of microglia in the rd10;Muty $h^{+/+}$ mice, at least in part (Figure 4C).

We next investigated the formation of ssDNA and the activation of PARP in microglia. The microglia were associated with the accumulation of SSBs and PAR in the rd10;Muty $h^{+/+}$mice at P17 and P21 (Figure 5, A-D). In contrast, MUTYH deficiency prevented the SSB formation and PARP activation in microglial cells at both time points (Figure 5, A-D). These findings suggest that oxidative DNA damage in microglia triggers microglial activation and promotes photoreceptor degeneration through MUTYH-mediated BER.

MUTYH mediates the activity and cytotoxicity of primary microglial cells under oxidative stress. To test whether MUTYH mediates microglial activation under oxidative stress, we conducted in vitro experiments using primary microglial cells isolated from the brains of $\mathrm{rd10} M \mathrm{Muty}^{\mathrm{h}^{++}}$and $\mathrm{rd} 10 ; M u t y h^{-/-}$mice. Because PDE6 $\beta$ is exclusively expressed in rod photoreceptor cells in the retina, rd10 mutation may not influence 


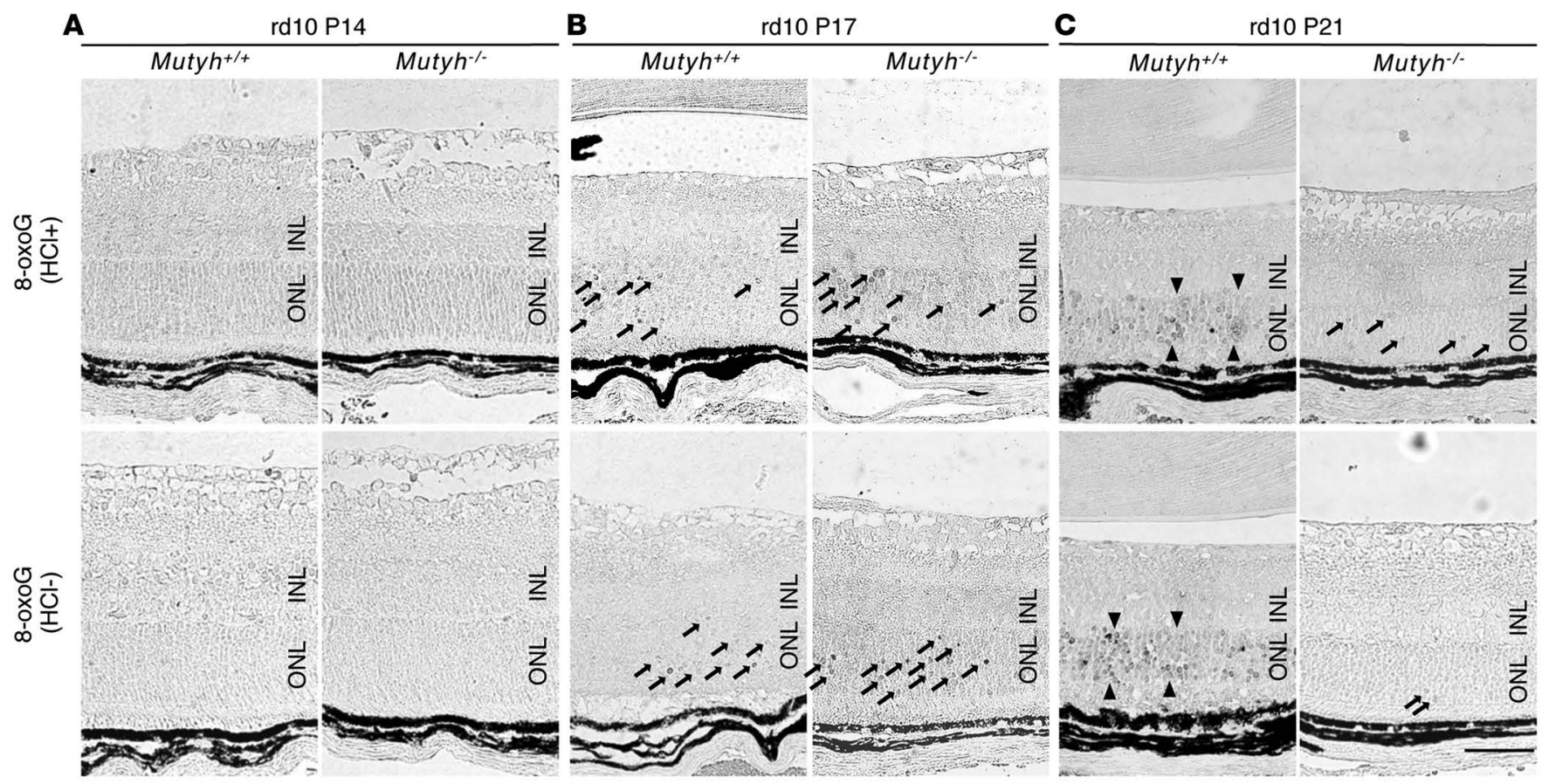

Figure 3. Mutyh deficiency suppressed the expansion of retinal oxidative DNA damage in rd10 mice. (A-C) Immunohistochemical detection of

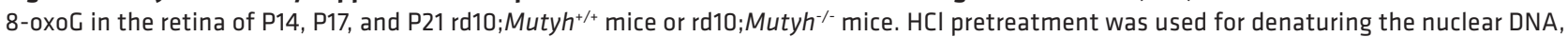
thereby enhancing the detection of 8-oxoG in nuclear DNA. The accumulation of 8-oxoG was not observed in the retinas of the rd10; $\mathrm{Mutyh}^{+/+}$mice or rd10;Muty $h^{-1 /}$ mice at P14 (A). Scattered accumulation of 8-oxoG was observed at P17 (arrows), and the staining pattern was comparable between the

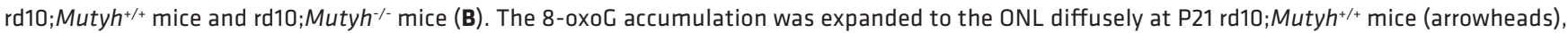
whereas it was substantially suppressed in rd10;Mutyh ${ }^{-/-}$mice (arrows) (C). INL, inner nuclear layer; ONL, outer nuclear layer. Scale bar: $50 \mu \mathrm{m}$. Figures show the representative results from 3 experiments.

the baseline microglial activity in the brain. Indeed, there was no obvious morphological difference in the brain microglia between the rd10;Muty $h^{+/+}$and rd10;Muty $h^{-/-}$mice (Supplemental Figure 5). The purity of the Iba-1-positive microglia in the primary culture was $>95 \%$ (Supplemental Figure 6), and the loss of Mutyh expression in microglial cells isolated from the rd10;Muty $h^{-/-}$brain (Muty $h^{-/-}$microglia) was confirmed by PCR (Supplemental Figure 7).

We first examined the accumulation of SSBs and PAR under normal and oxidative conditions. We used menadione, which increases ROS by depleting NADPH (33), to cause oxidative DNA damage to microglial cells. Immunostaining demonstrated that menadione induced an accumulation of SSBs and PAR in $\mathrm{Mutyh}^{+/+}$microglia, while these accumulations were suppressed in $\mathrm{Mutyh}^{-/-}$microglia (Figure 6, A and B, and Supplemental Figure 8).

Next, we investigated the activation status of microglia. CD206 is a scavenger receptor that facilitates the clearance of dying or dead cells, and it mediates neuroprotective and antiinflammatory effects in neurodegeneration (34). MUTYH deficiency suppressed the reduction of CD206 expression that was induced by menadione (Figure 6, A and B, and Supplemental Figure 8). In contrast, the menadione treatment increased the production of TNF- $\alpha$ from microglial cells, which was reversed by MUTYH deficiency (Figure $6 \mathrm{C})$. The cell viability of the microglial cells was not severely affected by the menadione treatment, and there was no difference between the $\mathrm{Muty}^{h^{+/+}}$and $\mathrm{Muty}^{h^{-/-}}$microglia (Supplemental Figure 9).

We then cocultured microglial cells with $661 \mathrm{~W}$ photoreceptor cells to evaluate the cytotoxicity of microglial cells. The results of the lactate dehydrogenase $(\mathrm{LDH})$ assay showed that there was only a low level of $\mathrm{LDH}$ release from $661 \mathrm{~W}$ cells cocultured with unstimulated $M u t y h^{+/+}$or $M u t y h^{-/-}$microglia. The coculture of $661 \mathrm{~W}$ cells with menadione-treated $\mathrm{Muty}^{h^{+/+}}$microglia resulted in a substantially increased LDH release in a menadione dose-dependent manner. This menadione-induced microglial cytotoxicity was completely reversed by MUTYH deficiency (Figure 6D). The LDH levels released from microglial cells alone after menadione treatment were $<2 \%$ of the maximal $\mathrm{LDH}$ amounts, indicating that the $\mathrm{LDH}$ increases observed in the coculture experiments were derived mainly from damaged 661W cells (Supplemental Figure 10). 
A
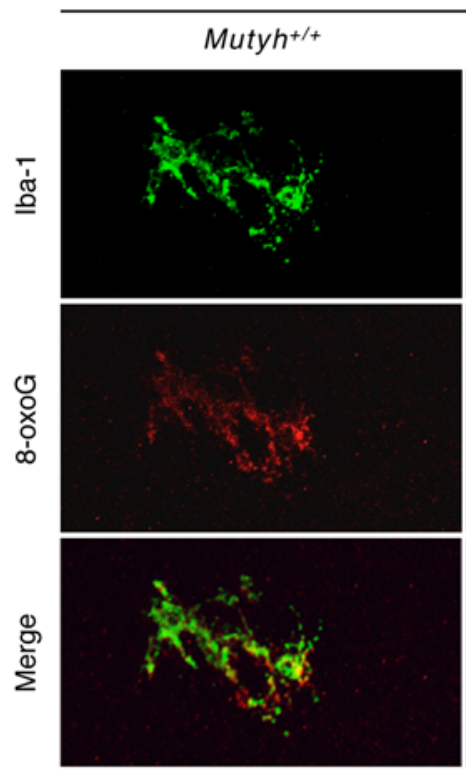

C

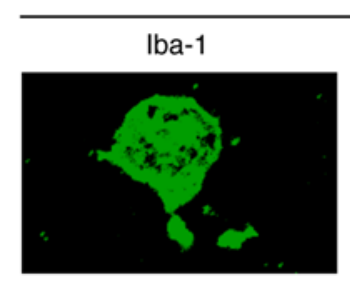

rd10 P17

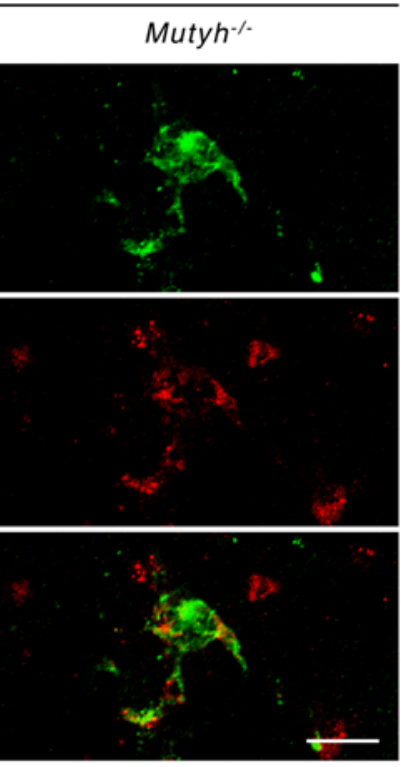

B

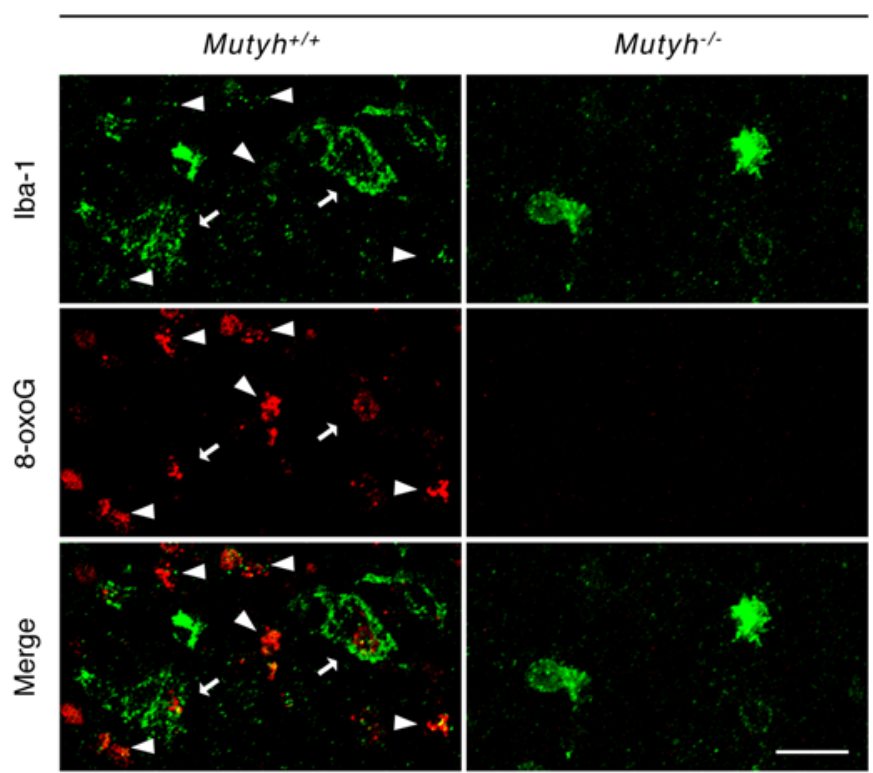

Figure 4. Oxidative DNA damage targeted microglia in early phase of retinal degeneration in rd10 mice. (A and B) Iba-1 (green) and 8-oxoG (red) staining in the retinas of P17 (A) and P21 (B) rd10;Mutyh ${ }^{+/+}$mice or rd10;Mutyh ${ }^{-/-}$mice. (A) Part of 8-oxoG signals were colocalized in Iba-1-positive microglia in the retinas of the rd10; Mutyh $^{+/+}$mice and rd10;Mutyh/- mice at P17. Scale bar: $20 \mu \mathrm{m}$. (B) Increased 8-oxoG accumulation was observed in the photoreceptor layer, as well as microglial cells in rd10;Mutyh ${ }^{+/+}$mice at P21, whereas they were substantially prevented in the retinas of rd10;Muty ${ }^{-/-}$mice. The arrows indicate colocalization of Iba-1-positive microglia and 8-oxoG. The arrowheads indicate the cells positive for 8-oxoG but negative for Iba-1. Scale bar: 20

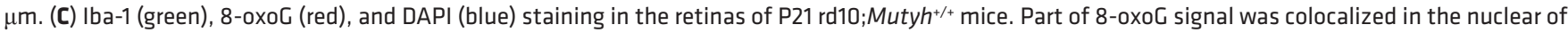
Iba-1-positive microglia in the retina of rd10; $\mathrm{Mutyh}^{+/+}$mice at $\mathrm{P} 21$. Scale bar: $5 \mu \mathrm{m}$. All samples in this figure were treated with $2 \mathrm{~N} \mathrm{HCl}(\mathrm{HCl}+)$ to enhance the 8-oxoG signal in nuclear DNA. Figures show the representative results from 3 experiments.

To assess the influence of MUTYH deficiency on the microglial activation or polarization of microglia in the retina of rd10 mice, we performed retinal whole-mount staining for Iba- 1 and TNF- $\alpha$ or CD206. MUTYH deficiency suppressed the expression of TNF- $\alpha$ in microglia (Figure 7A) and increased CD206-positive microglia in the retina of P21 rd10 mice (Figure 7B). Taken together, these findings indicate that MUTYH is pivotal for microglial activation and neurotoxicity under oxidative damage.

\section{Discussion}

Oxidative damage to nucleic acids, as well as proteins and lipids, is implicated in the pathology of the genetically heterogeneous group of RP disease; however, the molecular and biological mechanisms by which oxidative damage mediates retinal degeneration remain largely unknown. We reported that the transgenic overexpression of MTH1 attenuated retinal oxidative DNA damage in rd10 mice, indicating that oxidized nucleotides in the nucleotide pool are incorporated into the DNA during retinal degeneration (16). Our present findings further demonstrated that MUTYH-mediated BER against DNA oxidation is critical for SSB formation in the retinas of $\mathrm{rd} 10$ mice. Our results also revealed that oxidative DNA damage is accumulated in microglia in the early stage of retinal degeneration and that MUTYH mediates the microglial activation and neurotoxicity, thereby promoting retinal inflammation and degeneration in rd10 mice. These findings suggest a mechanism of retinal degeneration in $\mathrm{RP}$, in which 
A
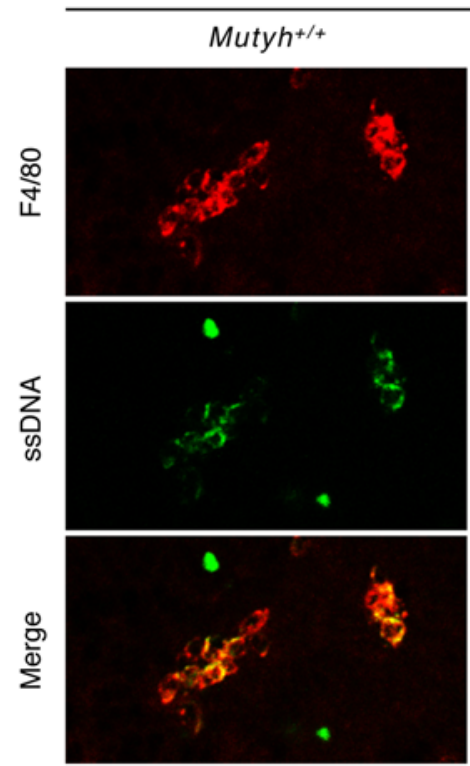

C

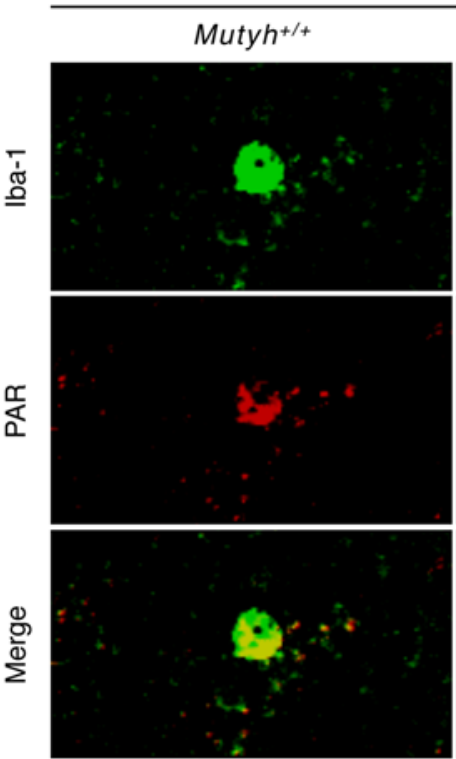

d10 P17

Mutyh $^{-/}$
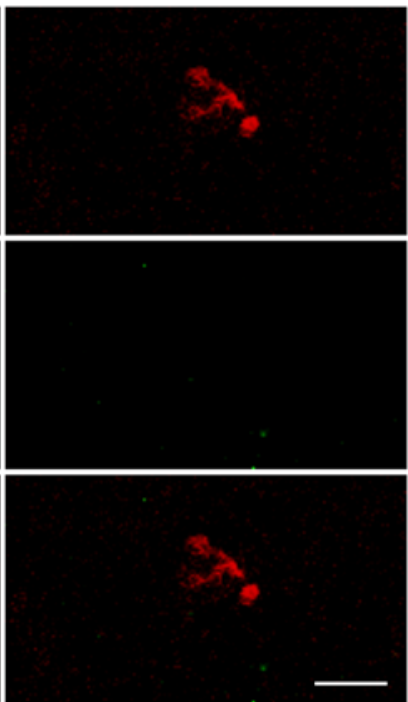

rd10 P17

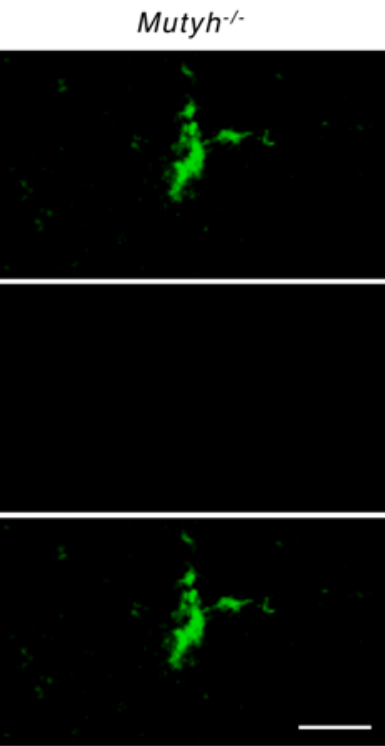

B

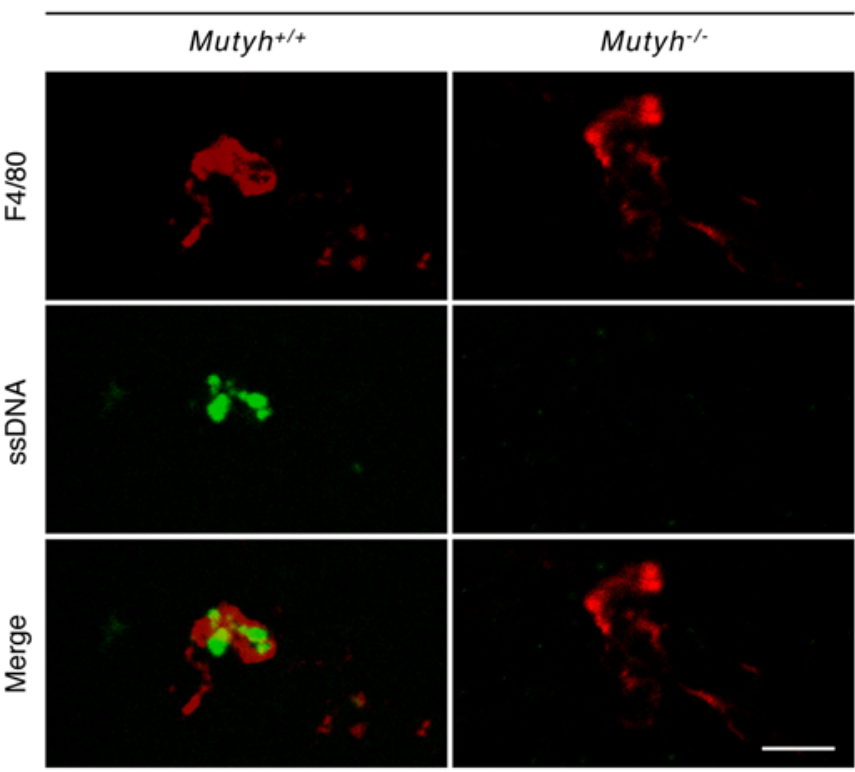

D

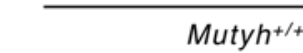

rd10 P21

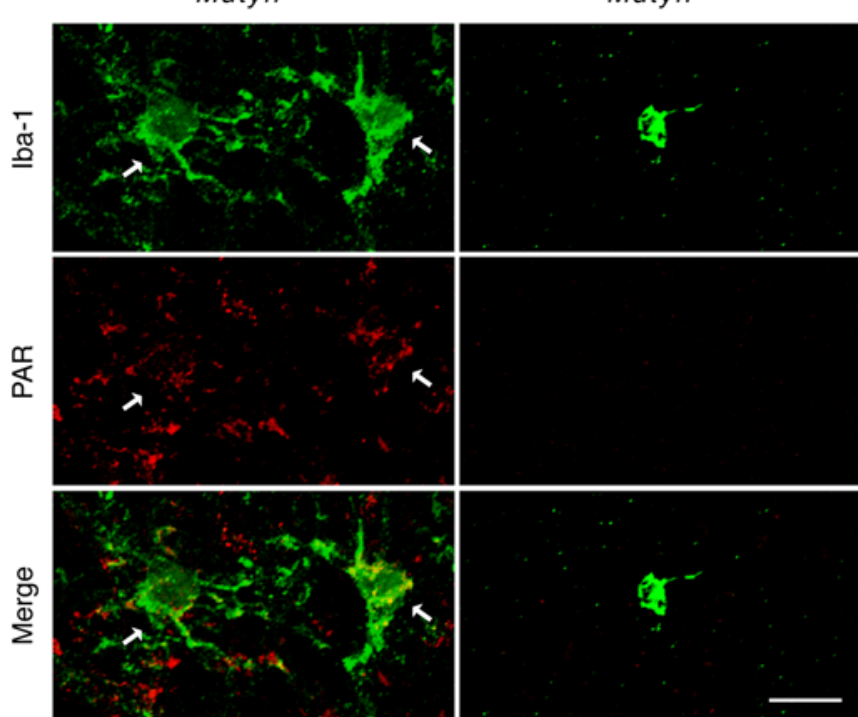

Figure 5. Mutyh deficiency suppressed the microglial SSBs formation and PARP activation in rd10 mice. (A and B) ssDNA (green) and F4/80 (red) staining in the retinas of P17 (A) and P21 (B) rd10;Mutyh $h^{+/}$mice or rd10;Mutyh ${ }^{-/-}$mice. The microglia were associated with the accumulation of SSBs in rd10; Muty $h^{+/+}$mice. In contrast, Mutyh deficiency prevented the SSBs formation in microglial cells at both P17 (A) and P21 (B). (C and D) Iba-1 (green) and PAR (red) staining in the retinas of P17 or P21 rd10;Muty $h^{+/+}$mice or rd10;Mutyh ${ }^{-/}$mice. Mutyh deficiency suppressed the PAR accumulation in microglia at both P17 (C) and P21 (D). The arrows indicate the colocalization of Iba-1-positive microglia and PAR (D). Scale bars: $20 \mu \mathrm{m}$. Figures show representative results from 3 experiments.

oxidative DNA damage to microglia triggers microglial activation and exacerbates photoreceptor cell death through MUTYH-mediated BER.

Inflammation in RP was thought to be a secondary event of primary photoreceptor cell death due to genetic mutations; however, an accumulating body of evidence suggests that chronic inflammation may contribute to the progression of rod and cone degeneration in RP. In the eyes of human RP patients, microglial cell infiltration was observed in the transition zone between relatively healthy and degenerated retina, an active region of vision loss (35). We recently reported that the ocular inflammatory levels of RP patients are negatively correlated with visual function $(36,37)$. In animal models of RP, it was shown that 
A

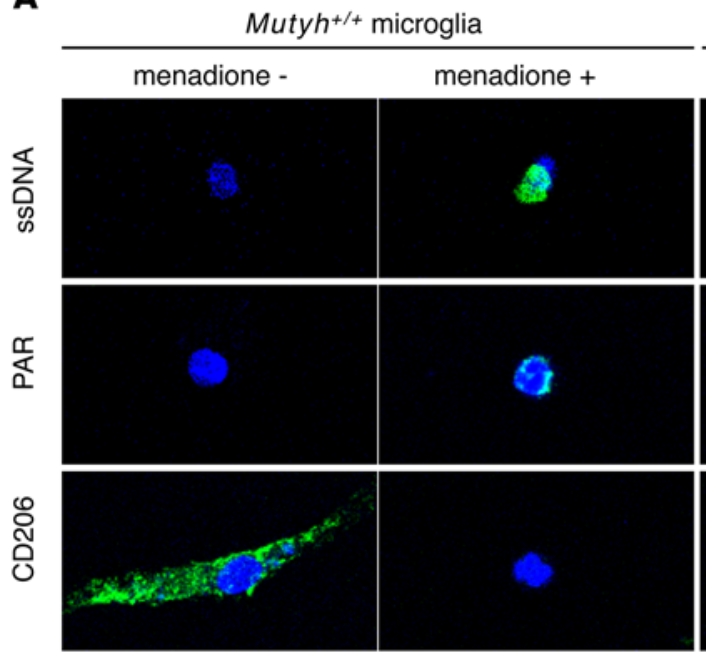

Mutyh ${ }^{\circ}$ microglia

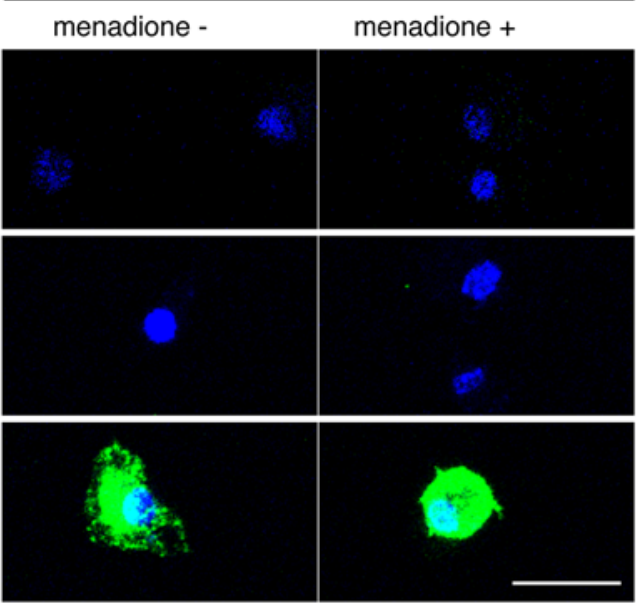

C

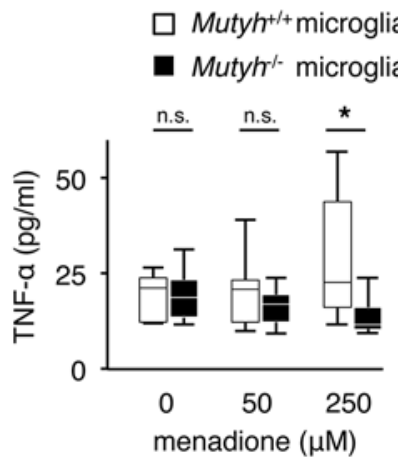

D

D coculture of $661 \mathrm{~W}$ cells with

O Mutyht/+microglia

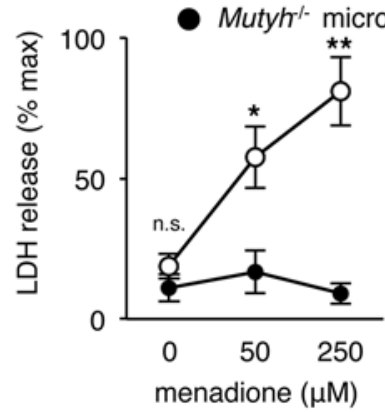

B $\square$ Mutyh $h^{+/+}$microglia
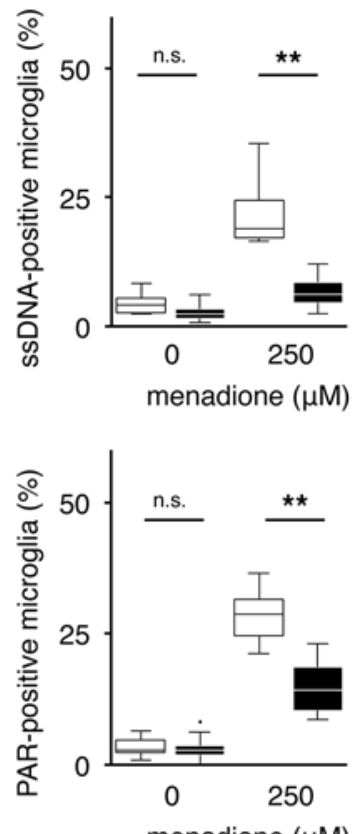

menadione $(\mu \mathrm{M})$

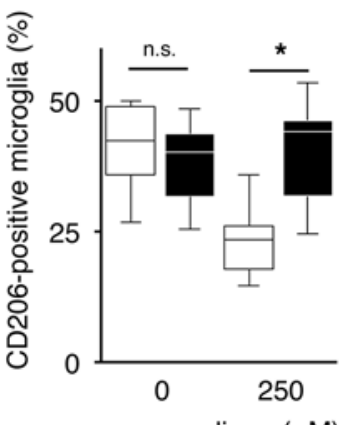

Figure 6. MUTYH mediated the activity and cytotoxicity of primary microglial cells under oxidative stress. (A and B) Immunostaining for ssDNA, PAR, and CD206 (A) and the quantification of ssDNA-, PAR-, CD206-positive microglial cells (B) in Mutyh $h^{+/+}\left(n=6\right.$, each) or Mutyh $h^{-/-}(n=6$, each) microglia. (A) ssDNA (green) and DAPI (blue) staining (upper panel), PAR (green) and DAPI (blue) staining (middle panel), and CD206 (green) and DAPI (blue) staining (lower panel). (B) Quantification of the ratio of ssDNA-positive microglial cells (upper graph), PAR-positive microglial cells (middle graph) and CD206positive microglial cells (lower graph). Microglial cells were treated in the presence or absence of $250 \mu \mathrm{M}$ menadione for 24 hr. More than 100 microglial cells per well were evaluated. Mutyh deficiency suppressed the SSBs and PAR accumulation and prevented the reduction of CD206 expression after menadione exposure. Scale bar: $20 \mu \mathrm{m}$. (C) ELISA for TNF- $\alpha$ in the supernatants of Muty $h^{+/+}(n=7)$ or Mutyh ${ }^{-/-}(n=6)$ microglia. Microglial cells were treated with menadione for $24 \mathrm{hr}$ at the indicated concentrations. (D) Cell toxicity of microglial cells to 661W photoreceptor cells. Muty $h^{+/+}(n=8)$ or Mutyh ${ }^{-/}(n=$ 14) microglia were treated with menadione for $6 \mathrm{hr}$ at the indicated concentrations. After being washed with PBS, the activated microglia were cocultured with $661 \mathrm{~W}$ photoreceptor cells for $24 \mathrm{hr}$ and the supernatants were subjected to an LDH assay. Mutyh deficiency reduced the cell toxicity of microglial cells induced by menadione. Figures shown are the representative results from 3 experiments (A), and the data shown are the combined results of 3-4 experiments (B-D). Data are presented as whisker-box plots. The central horizontal bars indicate the medians, boxes indicate 25 th to 75 th percentiles, and whiskers indicate 1.5 times the interquartile range from the bottom and the top of the box $(\mathbf{B}$ and $\mathbf{C})$. Outliers are shown as dots. Error bar: mean \pm SEM (D). Student's $t$ tests were performed to assess the significance. ${ }^{*} P<0.05,{ }^{* *} P<0.01$.

microglia migrate into the ONL at the onset of or before photoreceptor cell death $(10,38)$, and the suppression of microglial activation ameliorates photoreceptor cell loss (32). However, the mechanisms underlying microglial activation in RP have not been fully elucidated.

The results of the present study revealed that oxidative DNA damage promotes microglial activation through MUTYH-mediated BER during retinal degeneration. DNA oxidation in microglia, as well as in neuronal cells, has been demonstrated in kainate-induced or 3-nitropropionic acid-induced (3-NP-induced) neurodegeneration $(23,39)$, although it has not been determined which cells - microglia or neuronal cells 
A

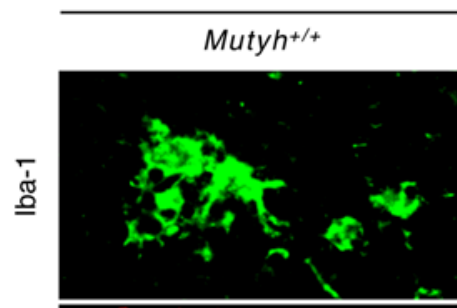

rd10 P21
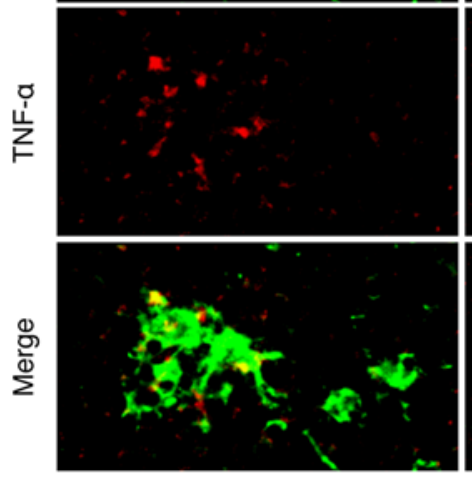

B

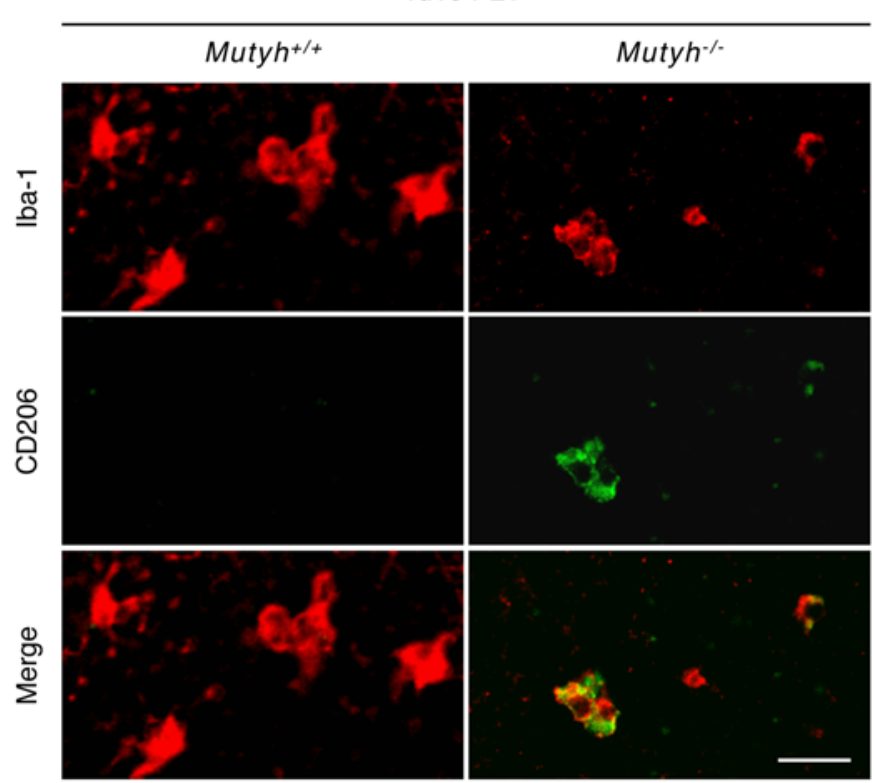

Figure 7. MUTYH mediated the TNF- $\alpha$ secretion and polarization of microglia in rd10 mice. (A) Iba-1 (green) and TNF- $\alpha$ (red) staining in the retinas of P21 rd10; Muty $h^{+/+}$mice or rd10;Mutyh ${ }^{-/-}$mice. In the rd10;Muty $h^{+/+}$mice, the microglia in retinas expressed TNF- $\alpha$. In contrast, Mutyh deficiency suppressed the expression of TNF- $\alpha$ in microglia. (B) Iba-1 (red) and CD206 (green) staining in the retinas of P21 rd10;Muty H/+ $^{+/}$mice and rd10;Mutyh ${ }^{-/-}$mice. There were few CD206-positive microglia in the retinas of the rd10;Muty $\mathrm{h}^{+/+}$mice. In contrast, Mutyh deficiency increased CD206-positive microglia. Scale bars: $20 \mu \mathrm{m}$. Figures show the representative results from 3 experiments.

- are the primary targets of oxidative damage. The results of the present investigation showed that, in rd10 mice, nuclear DNA oxidation occurs in the microglia before the peak of photoreceptor degeneration and thereafter expands to the photoreceptor nuclei, along with microglial activation. These findings suggest that oxidative DNA damage in microglia is critical for promoting the cycle of inflammation and photoreceptor cell death in RP. Because the incorporation of 8-oxoG into the template DNA and MUTYH-mediated BER occur during DNA replication $(19,20)$, it is reasonable that MUTYH functions in the nuclei of mitotic microglia rather than the nuclei of postmitotic photoreceptor cells.

However, because various cell types could be affected by systemic Mutyh deficiency, we cannot exclude the possibility that MUTYH acts directly on photoreceptor cells and induces cell death in rd10 mice. MUTYH-mediated BER forms single- or double-stranded breaks of DNA and induces cell death under severe oxidative stress in diverse cell types, indicating these events as an important mechanism of cell death conserved from bacteria to mammals $(21,23,40,41)$. Further studies using microglia- or photoreceptor-specific Mutyh KOs are needed to elucidate the precise mechanisms by which oxidative DNA damage promotes retinal inflammation and degeneration in rd10 mice.

We reported that, in mouse embryonic fibroblasts, DNA oxidation in the nucleus and mitochondria induces SSBs through MUTYH activity and triggers 2 distinct pathways: nuclear DNA oxidation mediates PARP activation, and mitochondrial DNA oxidation activates calpain (21). Sheng et al. demonstrated that 3-NP exposure induces nuclear DNA oxidation and PARP activation in striatal microglia; it also induces mitochondrial DNA oxidation and calpain activation in medium spiny neurons (23), whereas isolated neurons from MTH1/OGG1 double-deficient mice accumulated 8-oxoG only in mitochondrial DNA, and the mice thus underwent impaired neuritogenesis in vitro (42). Consistent with these findings, our present in vitro and in vivo experiments showed that nuclear DNA oxidation in microglia is associated with PARP activation, which was reversed by MUTYH deficiency. Previous studies showed that PARP is essential for microglial activation in experimental models of neuronal damage (43-45). The results of the present and previous studies suggest that oxidative nuclear DNA damage and MUTYH are critical upstream regulators of microglial PARP activity during neurodegeneration.

Our present findings revealed that MUTYH-deficient microglia exhibited reduced TNF- $\alpha$ production and preserved CD206 expression under oxidative stress in vitro and in vivo. TNF- $\alpha$ is a proinflammato- 
ry cytokine that is released in response to infection and tissue injury, as well as DNA damage $(46,47)$. It also induces cell death through the direct activation of caspases/receptor-interacting protein kinases or indirectly via the activation of inflammatory cells. TNF- $\alpha$ expression is increased in the retinas of animal models of RP, as well as the vitreous of RP patients $(10,36)$. In addition, TNF- $\alpha$ blockade by infliximab suppressed photoreceptor cell death in an in vitro model of RP, indicating the detrimental role of TNF- $\alpha$ in retinal degeneration (48). In contrast, CD206 (also called mannose receptor) mediates antiinflammatory and neuroprotective functions with scavenger receptor activity (34). These findings suggest that MUTYH may promote retinal degeneration through the polarization of microglia toward the activated phenotype under oxidative DNA damage.

It is currently unclear why the DNA of microglia, which do not express the mutant gene, is oxidized in rd10 mice. Since microglia interact dynamically with dying or dead rod photoreceptor cells (which are associated with increased ROS generation) in the early stage of retinal degeneration (49), the phagocytosis of these cells may contribute to the oxidative damage to microglia. In addition, the detailed signaling cascades by which MUTYH mediates microglial activation remain unknown. Although our present findings suggest the PARP pathway as a downstream event of MUTYH activation, previous studies demonstrated that JNK $(50,51)$ and NF- $\mathrm{KB}(52,53)$ are also activated in response to DNA damage. The mechanisms of microglial oxidation in RP warrant further investigation.

Oxidative stress mediates diverse biological functions and signals, including both cell death and survival (54). Although systemic treatments with high-dose antioxidants protected photoreceptor cells in experimental models of RP $(6,7)$, such interventions with much higher doses than those used for dietary supplements can be deleterious to organ systems. In the present study, we demonstrated that MUTYH in retinal microglia is a therapeutic target that mediates the retinal inflammation and degeneration downstream of oxidative DNA damage. Kim et al. demonstrated a method to deliver small interfering RNA selectively to microglia/macrophages, and they showed that the suppression of TNF- $\alpha$ in microglia ameliorates lipopolysaccharide-induced neuroinflammation and degeneration (55). The application of these techniques to inhibit MUTYH in retinal microglia may thus be an effective approach to combat detrimental oxidative damage in RP. Although MUTYH deficiency leads to cancer formation in mice and humans (56-58), selective knockdown in terminally differentiated cells such as microglia may result in a minimal risk of tumorigenesis.

In conclusion, our data showed that oxidative DNA damage activates microglia during MUTYHmediated BER, thereby promoting retinal inflammation and degeneration in a mouse model of RP. These findings suggest that MUTYH in oxidative microglial activation may be a potential therapeutic target for RP and other neurodegenerative diseases associated with oxidative stress and neuroinflammation.

\section{Methods}

Supplemental Methods are available online with this article.

Animals. WT (C57BL/6J) mice and B6.CXB1-Pde6 $\beta^{\text {rd10 } / J ~(r d 10) ~ m i c e ~ w e r e ~ p u r c h a s e d ~ f r o m ~ T h e ~ J a c k s o n ~}$ Laboratory. Mutyh KO (Muty $\left.h^{-/-}\right)$mice were established as described (20, 57). Rd10 mice were crossed with $\mathrm{Muty}^{-{ }^{-/}}$mice to generate rd10;Muty $\mathrm{h}^{-/-}$mice for more than 10 generations. Rd10 mutation in the Pde6b gene was detected by PCR with the use of the forward primer 5'-TCTCAGAACCCACATGTACT-3' and reverse primer 5'-TGATTCATCTAGCCCATCCA-3' and subsequent direct DNA sequencing using a Hitachi 3500xl Genetic Analyzer (Applied Biosystems). The Mutyh genotype was analyzed as described (57) by PCR using the forward primer 5'-CCTGGTGCAAAGGCCTGA-3' and the reverse primer 5'-GCAGTAGACACAGCTGCAT-3' to detect the WT allele, and the forward primer 5'-CTACGCATCGGTAATGAAGG-3' and the reverse primer 5'-GCAGTAGACACAGCTGCAT-3' to detect the $M u t y h^{-}$allele. Both sexes were used in this study.

Western blotting. Mouse eyes were enucleated and protein was extracted from the retinas by T-PER Tissue Protein Extraction Reagent (Thermo Fisher Scientific). Retinal protein (30 $\mu \mathrm{g})$ was subjected to SDSPAGE and transferred onto a polyvinylidene difluoride membrane. The membranes were blocked with Starting Block T20 Blocking Buffer (Thermo Fisher Scientific) for $30 \mathrm{~min}$ and then incubated with rabbit anti-hMUTYH antibody, as previously described, $(1: 3,500)$ at $4^{\circ} \mathrm{C}$ overnight $(59)$. After being washed with Tris-buffered saline containing $0.1 \%$ Tween, the membranes were incubated with anti-rabbit secondary antibody labeled with horseradish peroxidase (Envision ${ }^{+}$System, Dako), and signals were developed by chemiluminescence with SuperSignal West Femto (Thermo Fisher Scientific). Lane-loading differences were normalized by $\beta$-actin (1:1,000, 4967, Cell Signaling Technology). 
Retinal whole-mount staining. Mouse eyes were enucleated and fixed with $4 \%$ paraformaldehyde (PFA) for $1 \mathrm{hr}$ at $4^{\circ} \mathrm{C}$. After removal of the corneas and lenses, the retinas were blocked for $1 \mathrm{hr}$ with PBS containing $10 \%$ nonfat dried milk and 0.3\% Triton-X 100 (Wako [9002-93-1]). The retinas were then incubated with rabbit anti-Iba-1 antibody (1:100, 019-19741, Wako), Alexa Fluor 647-conjugated rat anti-F4/80 antibody (1:100, 123121, BioLegend), rabbit anti-ssDNA antibody (1:100, 18731, Immuno-Biological Laboratories), mouse anti- PAR antibody (1:100, 4336-APC-050, Trevigen), FITC-conjugated PNA (1:100, L7381, Sigma-Aldrich), mouse anti-TNF- $\alpha$ antibody (1:100, ab1793, Abcam) or Alexa Fluor 488-conjugated rat antimouse CD206 antibody (1:100, 141710, BioLegend) at $4^{\circ} \mathrm{C}$ overnight.

After being washed with PBS, the retinas were incubated with appropriate Alexa Fluor 488- or Alexa Fluor 647-conjugated secondary antibodies (Invitrogen) for $1 \mathrm{hr}$ at room temperature (RT) and then mounted on slides. To assess the number of microglia in the retina, we counted the Iba-1-positive cells in $0.25-\mathrm{mm}^{2}$ retinal areas in the superior, inferior, temporal, and nasal areas located $250 \mu \mathrm{m}, 500 \mu \mathrm{m}$, and $1,000 \mu \mathrm{m}$ from the optic disc. To assess the number of cone photoreceptor cells, we counted the PNA-positive cells in $0.015625-\mathrm{mm}^{2}$ retinal areas in the superior, inferior, temporal, and nasal areas located $250 \mu \mathrm{m}$, $500 \mu \mathrm{m}$, and 1,000 $\mu \mathrm{m}$ from the optic disc. The names and conditions of the samples were masked from the observers. The number of Iba-1-positive cells or PNA-positive cells was averaged, as were the numbers of the 4 retinal areas in each location $(250 \mu \mathrm{m}, 500 \mu \mathrm{m}$, and 1,000 $\mu \mathrm{m})$. Immunofluorescence images were acquired using a confocal microscope (A1R, Nikon).

Retinal section staining. Mouse eyes were enucleated and fixed with $4 \% \mathrm{PFA}$ at $4^{\circ} \mathrm{C}$ overnight and paraffinized. Sections (3- $\mu \mathrm{m}$ thick) were incubated with rabbit anti-ssDNA antibody (1:100, 18731, Immuno-Biological Laboratories) and mouse anti-PAR antibody (1:100, 4336-APC-050, Trevigen) at $4^{\circ} \mathrm{C}$ overnight. After being washed with PBS, the sections were incubated with Alexa Fluor 488-conjugated secondary antibody (Invitrogen) for $1 \mathrm{hr}$ at RT, and the nuclei were counterstained with DAPI. The numbers of ssDNA-positive cells and PAR-positive cells in $10,000-\mu \mathrm{m}^{2}$ areas in the central, mid-peripheral (mid), and peripheral regions of the nasal and temporal hemisphere were each counted in a masked fashion. The ONL areas in each square area were measured by using Image J version $1.47 \mathrm{v}$ (US NIH). The density of ssDNAor PAR-positive cells in the ONL was calculated and is expressed as cells $/ \mathrm{mm}^{2}$.

TUNEL staining. TUNEL staining was performed using an ApopTag Fluorescein In Situ Apoptosis Detection Kit (Merck Millipore) according to the manufacturer's instructions. The numbers of TUNEL-positive cells in 10,000- $\mu \mathrm{m}^{2}$ areas in the central, mid, and peripheral regions of the nasal and temporal hemispheres were counted in a masked fashion. The ONL areas in each square area were measured, and the density of TUNEL-positive cells in the ONL was calculated and is expressed as cells $/ \mathrm{mm}^{2}$.

Photoreceptor cell counting. The number of nuclei in the ONL was counted as described (10). Briefly, deparaffinized retinal sections were stained with $\mathrm{H} \& \mathrm{E}$. Images were acquired using a phase contrast microscope (BX51, Olympus). The numbers of nuclei in $10,000-\mu \mathrm{m}^{2}$ areas in the central, mid, and peripheral regions of the nasal and temporal hemispheres were counted in a masked fashion.

Immunodetection of 8-oxoG. The immunodetection of 8-oxoG in DNA was performed as described $(16,60)$. For paraffinized samples, deparaffinized retinal sections were incubated with $5 \mathrm{mg} / \mathrm{mL}$ RNase (Sigma-Aldrich) at $37^{\circ} \mathrm{C}$ for $1 \mathrm{hr}$ followed by a wash with PBS. For the detection of 8-oxoG in cellular DNA, the RNase-treated sections were blocked for $1 \mathrm{hr}$ with PBS containing 5\% nonfat dried milk and 0.3\% Triton-X 100 and then incubated with N45.1 anti-8-oxoG antibody (1:100, MOG-020P, JaICA) at $4^{\circ} \mathrm{C}$ overnight.

For the detection of 8-oxoG in nuclear DNA, the RNase-treated sections were further treated with 2 $\mathrm{N} \mathrm{HCl}$ at RT for 10 min followed by treatment with Tris- $\mathrm{HCl}, \mathrm{pH} 7.5$, at RT for $10 \mathrm{~min}$, and then blocked and incubated with N45.1 anti-8-oxoG antibody at $4^{\circ} \mathrm{C}$ overnight. All sections were incubated with biotinylated secondary antibody (Vector Laboratories) at RT for $45 \mathrm{~min}$ and then processed with a Vectastain $\mathrm{ABC}$ Kit (Vector) according to the manufacturer's instructions. For the detection of the peroxidase signals, sections were incubated with $\mathrm{DAB}$ with nickel solution (Vector) for $2 \mathrm{~min}$ and immediately washed with distilled water. Images were acquired using an Olympus BX51 microscope.

For the retinal whole-mount staining, mouse eyes were enucleated and fixed with 4\% PFA for $1 \mathrm{hr}$ at $4^{\circ} \mathrm{C}$. After removal of the corneas and lenses, retinas were incubated with $5 \mathrm{mg} / \mathrm{ml}$ RNase (Sigma-Aldrich) at $37^{\circ} \mathrm{C}$ for $1 \mathrm{hr}$ followed by treatment with $2 \mathrm{~N} \mathrm{HCl}$ at $\mathrm{RT}$ for $10 \mathrm{~min}$ and treatment Tris- $\mathrm{HCl}, \mathrm{pH} \mathrm{7.5,} \mathrm{at}$ RT for $10 \mathrm{~min}$. The retinas were then blocked for $1 \mathrm{hr}$ with PBS containing $10 \%$ nonfat dried milk and $0.3 \%$ Triton-X 100, followed by incubation with anti-8-oxoG antibody (1:100, MOG-020P, JaICA) and rabbit anti-Iba-1 antibody (1:100, 019-19741, Wako) at $4^{\circ} \mathrm{C}$ overnight. After being washed with PBS, the retinas 
were incubated with appropriate Alexa Fluor 488- and Alexa Fluor 647-conjugated secondary antibodies (Invitrogen) for $1 \mathrm{hr}$ at RT and then mounted on slides. For the detection of nuclei, retinas were counterstained with DAPI before being mounted on slides.

Primary culture of microglial cells. Primary microglial cells were harvested as described $(61,62)$. The cerebral cortices of rd10 mice and rd10;Muty $h^{-/-}$mice at P1-P4 were collected. Cortical tissues were incubated with PBS containing $0.0625 \%$ trypsin (Thermo Fisher Scientific) and $0.1 \mathrm{mg} / \mathrm{ml}$ DNase (Roche Diagnostics) for 5 min at $37^{\circ} \mathrm{C}$ and washed. These mixed glial cells were cultured in DMEM (high glucose, Thermo Fisher Scientific) containing 10\% FBS, $100 \mathrm{U} / \mathrm{ml}$ penicillin, $100 \mu \mathrm{g} / \mathrm{ml}$ streptomycin, and $5 \mu \mathrm{g} / \mathrm{ml}$ insulin (Sigma-Aldrich) in a $75-\mathrm{cm}^{2}$ flask coated with poly-D-lysine (PDL) (Sigma-Aldrich). The medium was changed every 2-3 days. After culturing for $10-14$ days, the flask was shaken $\left(1000 \mathrm{~g}, 37^{\circ} \mathrm{C}, 10 \mathrm{~min}\right)$ and floating microglial cells were harvested. More than $95 \%$ of the collected cells were Iba-1-positive (Supplemental Figure 6).

Enzyme-linked immunosorbent assay. Microglial cells were plated on a 96-well PDL-coated plate at a density of $1.5 \times 10^{4}$ cells/well in DMEM with FBS and incubated for $24 \mathrm{hr}$. After incubation, the medium was changed to serum-free DMEM containing various concentrations of menadione $(0,50$, and $250 \mu \mathrm{M})$ (Sigma-Aldrich) and incubated for $24 \mathrm{hr}$. After incubation, the cellular supernatants were harvested and we evaluated the levels of TNF- $\alpha$ using an ELISA (R\&D Systems) according to the manufacturer's instructions.

Immunocytostaining. Microglial cells were plated on a 4-well slide chamber (Nunc, Thermo Fisher Scientific) in DMEM containing FBS and incubated for $24 \mathrm{hr}$. After incubation, the medium was changed to DMEM containing FBS with $(250 \mu \mathrm{M})$ or without $(0 \mu \mathrm{M})$ menadione and incubated for $24 \mathrm{hr}$. After the incubation, the cells were fixed with 4\% PFA at RT for $10 \mathrm{~min}$. After a wash with PBS, the cells were incubated with PBS with $0.3 \%$ Triton-X 100 for 5 min and blocked with PBS containing 10\% nonfat dried milk for $1 \mathrm{hr}$ at RT. After blocking, the cells were incubated with rabbit anti-ssDNA antibody (1:100, 18731, Immuno-Biological Laboratories), mouse anti-PAR antibody (1:100, 4336-APC-050, Trevigen), and Alexa Fluor 488-conjugated rat anti-mouse CD206 antibody (1:100, 141710, BioLegend) at $4^{\circ} \mathrm{C}$ overnight. After a wash with PBS, the cells were incubated with Alexa Fluor 488-conjugated secondary antibody for $1 \mathrm{hr}$ at RT and the nuclei were counterstained with DAPI. More than 100 microglial cells were counted per well, and the ratios of ssDNA, PAR, and CD206-positive microglial cells were calculated.

Coculture of microglial cells with $661 \mathrm{~W}$ photoreceptor cells and the LDH assay. To determine the cell toxicity of the activated microglia, we cocultured primary microglial cells with $661 \mathrm{~W}$ cells, a photoreceptor cell line, which were a gift from M.R. Al-Ubaidi, University of Oklahoma Health Sciences Center (Oklahoma City, Oklahoma, USA) (63). We cultured the 661W cells in DMEM (Sigma-Aldrich) containing 10\% FBS, $100 \mathrm{U} / \mathrm{ml}$ penicillin, and $100 \mu \mathrm{g} / \mathrm{ml}$ streptomycin. The $661 \mathrm{~W}$ cells were plated on a 96-well PDL-coated plate at a density of $1.5 \times 10^{4}$ cells/well, incubated for $48 \mathrm{hr}$, and washed with serum-free DMEM just before the coculture experiment.

Activated microglial cells were prepared as follows: primary microglial cells were treated with various concentrations of menadione $(0,50$, and $250 \mu \mathrm{M})$ and incubated for $6 \mathrm{hr}$. After a wash with serum-free DMEM, activated microglial cells were added to the $96-$ well plate containing $661 \mathrm{~W}$ cells. They were cocultured for $24 \mathrm{hr}$; then, the supernatants were subjected to the LDH assay using a Cytotoxicity Detection Kit (Roche Diagnostics). The maximum amount of releasable LDH enzyme activity was determined by lysing the $661 \mathrm{~W}$ cells with $0.1 \%$ Triton-X 100 . The percent cytotoxicity of each well was calculated as follows: (absorbance value of supernatant from each well/mean absorbance value of supernatants from 661W cells treated with Triton-X 100 well) $\times 100$.

Statistics. Statistical analyses were performed using JMP 11.0.0 (SAS Institute). Comparisons of data between 2 groups were analyzed by Student's $t$ test or the Wilcoxon rank sum test according to the data distribution. Differences were considered significant at $P<0.05$.

Study approval. All mice were treated in accordance with the standards of the Association for Research in Vision and Ophthalmology for the use of animals in ophthalmic and vision research. All experimental procedures were approved by the Committee for Animals, Recombinant DNA, and Infectious Pathogens Experiments at Kyushu University.

\section{Author contributions}

YM, YI, and YN designed the research; S. Nakatake, YM, NM, TT, NY, S. Notomi, TH, and SY conducted the experiments; S. Nakatake and KF performed the statistical analyses; S. Nakatake, YM, YI, TI, YN, and KHS interpreted the data; S. Nakatake, YM, YI, and YN wrote the manuscript. 


\section{Acknowledgments}

We thank M.R. Al-Ubaidi (University of Oklahoma Health Sciences Center) and H. Hara (Gifu Pharmaceutical University, Gifu, Japan) for providing $661 \mathrm{~W}$ cells and M. Arima and M. Kumano (Kyushu University) for their technical support for the experiments. We also appreciate K. Sakumi, S. Oka, and D. Tsuchimoto (Kyushu University) for the scientific discussions. This work was supported by the Japanese Ministry of Education, Culture, Sports, Science, and Technology, grants 25861637 (to YM) and 22221004 (to YN); a Japan Intractable Disease Research Foundation grant (to YM); a Japanese Retinitis Pigmentosa Society grant (to YM); a Rhoto Award grant (to YI); and a Takeda Science Foundation grant (to YI).

Address correspondence to: Yusuke Murakami or Yasuhiro Ikeda, Department of Ophthalmology, Graduate School of Medical Sciences, Kyushu University, 3-1-1 Maidashi, Higashi-ku, Fukuoka, 812 8582, Japan. Phone: 81.92.642.5648; E-mail: ymuraka3@med.kyushu-u.ac.jp (Y. Murakami). E-mail: ymoc1@pathol1.med.kyushu-u.ac.jp (Y. Ikeda). Or to: Yusaku Nakabeppu, Division of Neurofunctional Genomics, Department of Immunobiology and Neuroscience, Medical Institute of Bioregulation, Kyushu University, 3-1-1 Maidashi, Higashi-ku, Fukuoka, 812-8582, Japan. Phone: 81.92.642.6800; E-mail: yusaku@bioreg.kyushu-u.ac.jp.

1. Hartong DT, Berson EL, Dryja TP. Retinitis pigmentosa. Lancet. 2006;368(9549):1795-1809.

2. Daiger SP, Sullivan LS, Bowne SJ. Genes and mutations causing retinitis pigmentosa. Clin Genet. 2013;84(2):132-141.

3. Fahim AT, Daiger SP, Weleber RG. Retinitis Pigmentosa Overview. In: Pagon RA, Adam MP, Ardinger HH et al, eds. Gene Reviews Seattle, Washington: GeneReviews!;1993-2015. http://www.ncbi.nlm.nih.gov/books/NBK1417. Accessed August 18, 2016.

4. RetNet! Retinal Information Network. https://sph.uth.edu/Retnet. Accessed August 18, 2016.

5. Shen J, et al. Oxidative damage is a potential cause of cone cell death in retinitis pigmentosa. J Cell Physiol. 2005;203(3):457-464.

6. Komeima K, Rogers BS, Campochiaro PA. Antioxidants slow photoreceptor cell death in mouse models of retinitis pigmentosa. J Cell Physiol. 2007;213(3):809-815.

7. Komeima K, Rogers BS, Lu L, Campochiaro PA. Antioxidants reduce cone cell death in a model of retinitis pigmentosa. Proc Natl Acad Sci U S A. 2006;103(30):11300-11305.

8. Usui S, et al. Increased expression of catalase and superoxide dismutase 2 reduces cone cell death in retinitis pigmentosa. $M o l$ Ther. 2009;17(5):778-786.

9. Lee SY, et al. N-Acetylcysteine promotes long-term survival of cones in a model of retinitis pigmentosa. J Cell Physiol. 2011;226(7):1843-1849.

10. Yoshida N, et al. Laboratory evidence of sustained chronic inflammatory reaction in retinitis pigmentosa. Ophthalmology. 2013;120(1):e5-12.

11. Xiong W, MacColl Garfinkel AE, Li Y, Benowitz LI, Cepko CL. NRF2 promotes neuronal survival in neurodegeneration and acute nerve damage. J Clin Invest. 2015;125(4):1433-1445

12. Kasai H, Nishimura S. Hydroxylation of deoxyguanosine at the C-8 position by ascorbic acid and other reducing agents. Nucleic Acids Res. 1984;12(4):2137-2145.

13. Kunisada M, et al. 8-Oxoguanine formation induced by chronic UVB exposure makes Ogg1 knockout mice susceptible to skin carcinogenesis. Cancer Res. 2005;65(14):6006-6010.

14. Ohno M, et al. 8-oxoguanine causes spontaneous de novo germline mutations in mice. Sci Rep. 2014;4:4689.

15. Nakabeppu Y. Cellular levels of 8-oxoguanine in either DNA or the nucleotide pool play pivotal roles in carcinogenesis and survival of cancer cells. Int J Mol Sci. 2014;15(7):12543-12557.

16. Murakami Y, et al. MutT homolog-1 attenuates oxidative DNA damage and delays photoreceptor cell death in inherited retinal degeneration. Am J Pathol. 2012;181(4):1378-1386.

17. Shibutani S, Takeshita M, Grollman AP. Insertion of specific bases during DNA synthesis past the oxidation-damaged base 8-oxodG. Nature. 1991;349(6308):431-434.

18. Maki H, Sekiguchi M. MutT protein specifically hydrolyses a potent mutagenic substrate for DNA synthesis. Nature. 1992;355(6357):273-275.

19. Slupska MM, Baikalov C, Luther WM, Chiang JH, Wei YF, Miller JH. Cloning and sequencing a human homolog (hMYH) of the Escherichia coli mutY gene whose function is required for the repair of oxidative DNA damage. J Bacteriol. 1996;178(13):3885-3892.

20. Hirano S, et al. Mutator phenotype of MUTYH-null mouse embryonic stem cells. J Biol Chem. 2003;278(40):38121-38124.

21. Oka S, Ohno M, Tsuchimoto D, Sakumi K, Furuichi M, Nakabeppu Y. Two distinct pathways of cell death triggered by oxidative damage to nuclear and mitochondrial DNAs. EMBO J. 2008;27(2):421-432.

22. Oka S, Nakabeppu Y. DNA glycosylase encoded by MUTYH functions as a molecular switch for programmed cell death under oxidative stress to suppress tumorigenesis. Cancer Sci. 2011;102(4):677-682.

23. Sheng Z, et al. 8-Oxoguanine causes neurodegeneration during MUTYH-mediated DNA base excision repair. J Clin Invest. 2012;122(12):4344-4361.

24. Wu DC, Ré DB, Nagai M, Ischiropoulos H, Przedborski S. The inflammatory NADPH oxidase enzyme modulates motor neuron degeneration in amyotrophic lateral sclerosis mice. Proc Natl Acad Sci U S A. 2006;103(32):12132-12137.

25. Zeng H, Ding M, Chen XX, Lu Q. Microglial NADPH oxidase activation mediates rod cell death in the retinal degeneration in rd mice. Neuroscience. 2014;275:54-61. 
26. Gill AJ, et al. Heme oxygenase-1 deficiency accompanies neuropathogenesis of HIV-associated neurocognitive disorders. J Clin Invest. 2014;124(10):4459-4472.

27. Chang B, et al. Two mouse retinal degenerations caused by missense mutations in the beta-subunit of rod cGMP phosphodiesterase gene. Vision Res. 2007;47(5):624-633.

28. McLaughlin ME, Sandberg MA, Berson EL, Dryja TP. Recessive mutations in the gene encoding the beta-subunit of rod phosphodiesterase in patients with retinitis pigmentosa. Nat Genet. 1993;4(2):130-134.

29. Kauppinen TM, Swanson RA. The role of poly(ADP-ribose) polymerase-1 in CNS disease. Neuroscience. 2007;145(4):1267-1272.

30. Yu SW, et al. Mediation of poly(ADP-ribose) polymerase-1-dependent cell death by apoptosis-inducing factor. Science. 2002;297(5579):259-263.

31. Yu SW, et al. Apoptosis-inducing factor mediates poly(ADP-ribose) (PAR) polymer-induced cell death. Proc Natl Acad Sci USA 2006;103(48):18314-18319.

32. Peng B, Xiao J, Wang K, So KF, Tipoe GL, Lin B. Suppression of microglial activation is neuroprotective in a mouse model of human retinitis pigmentosa. J Neurosci. 2014;34(24):8139-8150.

33. Criddle DN, et al. Menadione-induced reactive oxygen species generation via redox cycling promotes apoptosis of murine pancreatic acinar cells. J Biol Chem. 2006;281(52):40485-40492.

34. Varnum MM, Ikezu T. The classification of microglial activation phenotypes on neurodegeneration and regeneration in Alzheimer's disease brain. Arch Immunol Ther Exp (Warsz). 2012;60(4):251-266.

35. Gupta N, Brown KE, Milam AH. Activated microglia in human retinitis pigmentosa, late-onset retinal degeneration, and age-related macular degeneration. Exp Eye Res. 2003;76(4):463-471.

36. Yoshida N, et al. Clinical evidence of sustained chronic inflammatory reaction in retinitis pigmentosa. Ophthalmology. 2013;120(1):100-105

37. Murakami Y, et al. Relationship between aqueous flare and visual function in retinitis pigmentosa. Am J Ophthalmol. 2015;159(5):958-63.e1.

38. Zeng HY, Zhu XA, Zhang C, Yang LP, Wu LM, Tso MO. Identification of sequential events and factors associated with microg lial activation, migration, and cytotoxicity in retinal degeneration in rd mice. Invest Ophthalmol Vis Sci. 2005;46(8):2992-2999.

39. Kajitani K, Yamaguchi H, Dan Y, Furuichi M, Kang D, Nakabeppu Y. MTH1, an oxidized purine nucleoside triphosphatase, suppresses the accumulation of oxidative damage of nucleic acids in the hippocampal microglia during kainate-induced excitotoxicity. J Neurosci. 2006;26(6):1688-1698.

40. Foti JJ, Devadoss B, Winkler JA, Collins JJ, Walker GC. Oxidation of the guanine nucleotide pool underlies cell death by bactericidal antibiotics. Science. 2012;336(6079):315-319.

41. Dwyer DJ, Collins JJ, Walker GC. Unraveling the physiological complexities of antibiotic lethality. Annu Rev Pharmacol Toxicol. 2015;55:313-332.

42. Leon J, Sakumi K, Castillo E, Sheng Z, Oka S, Nakabeppu Y. 8-Oxoguanine accumulation in mitochondrial DNA causes mitochondrial dysfunction and impairs neuritogenesis in cultured adult mouse cortical neurons under oxidative conditions. Sci Rep. 2016;6:22086.

43. Ullrich O, Diestel A, Eyüpoglu IY, Nitsch R. Regulation of microglial expression of integrins by poly(ADP-ribose) polymerase-1. Nat Cell Biol. 2001;3(12):1035-1042.

44. Kauppinen TM, Swanson RA. Poly(ADP-ribose) polymerase-1 promotes microglial activation, proliferation, and matrix metalloproteinase-9-mediated neuron death. J Immunol. 2005;174(4):2288-2296.

45. d'Avila JC, et al. Microglial activation induced by brain trauma is suppressed by post-injury treatment with a PARP inhibitor. $J$ Neuroinflammation. 2012;9:31.

46. Kibitel J, Hejmadi V, Alas L, O'Connor A, Sutherland BM, Yarosh D. UV-DNA damage in mouse and human cells induces the expression of tumor necrosis factor alpha. Photochem Photobiol. 1998;67(5):541-546.

47. Rodier F, et al. Persistent DNA damage signalling triggers senescence-associated inflammatory cytokine secretion. Nat Cell Biol. 2009;11(8):973-979.

48. Martínez-Fernández de la Cámara C, Olivares-González L, Hervás D, Salom D, Millán JM, Rodrigo R. Infliximab reduces Zaprinast-induced retinal degeneration in cultures of porcine retina. J Neuroinflammation. 2014;11:172.

49. Zhao L, et al. Microglial phagocytosis of living photoreceptors contributes to inherited retinal degeneration. EMBO Mol Med. 2015;7(9):1179-1197.

50. Yoshida K, Yamaguchi T, Natsume T, Kufe D, Miki Y. JNK phosphorylation of 14-3-3 proteins regulates nuclear targeting of c-Abl in the apoptotic response to DNA damage. Nat Cell Biol. 2005;7(3):278-285.

51. Hamdi M, et al. DNA damage in transcribed genes induces apoptosis via the JNK pathway and the JNK-phosphatase MKP-1 Oncogene. 2005;24(48):7135-7144.

52. Huang TT, Wuerzberger-Davis SM, Wu ZH, Miyamoto S. Sequential modification of NEMO/IKKgamma by SUMO-1 and ubiquitin mediates NF-kappaB activation by genotoxic stress. Cell. 2003;115(5):565-576

53. Wu ZH, Shi Y, Tibbetts RS, Miyamoto S. Molecular linkage between the kinase ATM and NF-kappaB signaling in response to genotoxic stimuli. Science. 2006;311(5764):1141-1146.

54. Haines DD, Juhasz B, Tosaki A. Management of multicellular senescence and oxidative stress. J Cell Mol Med. 2013;17(8):936-957.

55. Kim SS, et al. Targeted delivery of siRNA to macrophages for anti-inflammatory treatment. Mol Ther. 2010;18(5):993-1001.

56. Al-Tassan N, et al. Inherited variants of MYH associated with somatic G:C--> T:A mutations in colorectal tumors. Nat Genet. 2002;30(2):227-232.

57. Sakamoto K, et al. MUTYH-null mice are susceptible to spontaneous and oxidative stress induced intestinal tumorigenesis. Cancer Res. 2007;67(14):6599-6604

58. Nielsen M, Morreau H, Vasen HF, Hes FJ. MUTYH-associated polyposis (MAP). Crit Rev Oncol Hematol. 2011;79(1):1-16.

59. Ohtsubo T, et al. Identification of human MutY homolog (hMYH) as a repair enzyme for 2-hydroxyadenine in DNA and detection of multiple forms of hMYH located in nuclei and mitochondria. Nucleic Acids Res. 2000;28(6):1355-1364

60. Yamaguchi H, et al. MTH1, an oxidized purine nucleoside triphosphatase, protects the dopamine neurons from oxidative damage in nucleic acids caused by 1-methyl-4-phenyl-1,2,3,6-tetrahydropyridine. Cell Death Differ. 2006;13(4):551-563. 
61. Ifuku M, et al. Bradykinin-induced microglial migration mediated by B1-bradykinin receptors depends on Ca2+influx via reverse-mode activity of the $\mathrm{Na}+/ \mathrm{Ca} 2+$ exchanger. J Neurosci. 2007;27(48):13065-13073.

62. Nomaru H, et al. Fosb gene products contribute to excitotoxic microglial activation by regulating the expression of complement C5a receptors in microglia. Glia. 2014;62(8):1284-1298.

63. al-Ubaidi MR, et al. Bilateral retinal and brain tumors in transgenic mice expressing simian virus 40 large $\mathrm{T}$ antigen under control of the human interphotoreceptor retinoid-binding protein promoter. J Cell Biol. 1992;119(6):1681-1687. 